\title{
INTRODUCTION TO TEACHING AND LEARNING 'INTEL' - EFFICIENT PROFESSIONAL DEVELOPMENT THROUGHOUT A UNIVERSITY
}

\author{
Mikkel Godsk', Linda Greve ${ }^{2}$ \\ ${ }^{1}$ Science and Technology Lab, Aarhus University (DENMARK) \\ ${ }^{2}$ Centre for Teaching and Learning (DENMARK)
}

\begin{abstract}
Letting four educational units from each of the four faculties at Aarhus University co-create an online "one size fits all"-professional development course might sound like a hazardous decision. Both in terms of developing the course due to the many different approaches to professional development across the faculties and in terms of making the course relevant to the diverse group of participants ranging from tutors to professors in all kinds of different subject areas and teaching obligations.

Nevertheless, due to widely rooted project group with representatives from all faculties and a relatively early consensus on the overall framework conditions of the course, the course is now ready for pilot testing. It involves a design where content can be used flexibly according participant's needs and aiming at promoting educational 'design thinking' among the participants. The development process is inspired by the framework well-known from academic journals including an open call for contribution and a peer-review process and as such the overall development process has been relatively smooth. This paper presents both the underlying framework conditions for developing the course and the actualised design.
\end{abstract}

Keywords: Professional Development, Design Thinking, Online Course, Teaching Training.

\section{INTRODUCTION}

In order to meet new requirements for accreditation and quality assurance [1] the pro-rector for education initiated in the development of a 'one size fits all' professional development -course in 2015. The aim of the course was to provide basic professional development for all educators throughout the university. However tempting the idea it is far from trivial to design a course addressing all educators across subject areas, career levels, and teaching duties.

The result is an online course promoting educational 'design thinking', where the aim is to not only introduce to the educational context of the university and provide pedagogical knowledge but also to stimulate the participants thinking about the design of their teaching practice.

\subsection{Theoretical framework}

The theoretical foundations of the development of the course were derived from design thinking, active learning and technology-enhanced learning.

Design thinking is well known in innovation and entrepreneurship. As presented by Dorst [2], the use of the overall design-thinking framework has worked its way into education. The formula for the approach consists of three elements: 1 ) what - the thing or product, 2) how - the working principle and 3 ) the result in terms of aspired value.

In terms of educational design thinking the purpose is to get educators to understand their role in terms of learning experience designers rather than knowledge transmitters. This in turn calls for a deeper understanding among educators of both the what, i.e. the course they are teaching, the how, i.e. active learning, quality in teaching, structuring good teaching etc. and the results, i.e. the learning outcome and the use of the course in the student's further education. This approach to professional development is not new to the world, but it is new to the field of professional development. A number of barriers is to be expected. 
Inspired by Ertmer [3] and Tsai and Chai [4] the course aims at addressing three orders of barriers associated with educational development and technology integration. The first two orders are described as: 1) Extrinsic barriers e.g., technology, access to internet, access to computers, software, Learning Management Systems (LMS) and the like. 2) Intrinsic barriers e.g., culture, beliefs and attitude towards technology and change [3].

Tsai and Chai [4] extends the list by introducing third-order barriers as lack of design thinking, meaning that even though extrinsic and intrinsic barriers are overcome, the teacher still has to see him- or herself as the designer and developer of the course.

These barriers in turn are addressed actively in the course design and in the underlying framework conditions of constructing the course.

Active learning is another essential keystone of the course [5]. Using principles of constructive alignment both explicitly addressed in the course and as part of the mandatory learning path in the course, this is present at all levels of the course. The educators partaking in the course will experience explicit learning outcomes, activities throughout the learning paths and an assignment by the end of the course, which they ideally can bring directly into the classroom.

Last but not least the course development is inspired by experiences made in online and blended learning, e.g. [6]. The course is thus not made as a offline class put into an online setting. Rather it is designed to be an online course run by moderators. Text, videos and assignments are made by use of expertise in the four pedagogical units. Groups formed across the units played a significant role in producing content for the course.

Below the framework conditions of the course is outlined followed by an introduction to the actual design and rounded up by the future work of developing the course and using the data to be collected about educators in professional development in general.

\section{FRAMEWORK CONDITIONS}

Prior local experiences with providing online professional development have proven to be effective, flexible, scalable, and low-cost [7][8][9]. Furthermore, the idea of inciting the participants to design their own teaching practice has proven to be motivating and effective. Thus, the project group decided to build on these previous initiatives and experiences in designing this course. In order to comply with the diverse cohort and its different teaching cultures and approaches to professional development, it was necessary to provide a high degree of flexibility supporting different aims for participating in the module, the participants' diverse teaching obligations and activities, the different subject areas, different academic calendars (time- and pace flexibility), the different locations (place flexibility), and the diverse institutional contexts (e.g., local educational, administrative, and IT support). Summed up the framework conditions for the course were that it should be:

1 Cost-effective, i.e., the course should be cheap to run compared to the number of participants;

2 Easy to administer in terms of enrollment, assessment, and completion;

3 Continuously scalable according to fluctuating number of participants;

4 Flexible in time, pace, and place so that it fits the calendar of a busy educator;

5 Relevant to 'all' educators, 'all' subject areas', and address all 'main' teaching activities by means of a content that covers the most common educational challenges and topics at the university;

6 Relevant to its participants by (1) introducing to the context, including the services already provided by the educational units, media labs, and the IT department; and (2) providing basic pedagogical/teaching skills as further explicated in the learning goals (see Fig. 1);

7 Exemplary, i.e., that the course 'walks the talk' and thus also serves as a good example of how online teaching may be - pedagogically and technically - organised using the institution-wide LMS, Blackboard;

8 High quality by means of peer-reviewed materials and trained e-moderators; 
9 Addressing all three orders of barriers by (1) providing information about IT, media, and pedagogical services provided at the university; (2) introducing to the culture at the university, explain the importance of the topic (by the senior management), and address the participants in a prosaic and well-documented, academic language; and (3) activating the participants' 'design thinking' by including a compulsory online activity where they are required to develop a minor component of their future/existing teaching practice and share this with other participants and provide feedback.

\section{DESIGN OF 'INTEL'}

Designing the InTeL course called for unanimously agreed upon learning goals. The learning goals should not be aiming at the highest taxonomic levels. Rather they should target a development and application of a specific element in the participant's own teaching and thereby increase the focus on quality in teaching and design thinking:

\section{Upon completion of InTeL, participants will be able to:}

- Identify elements in own teaching, which can be developed in order to enhance student learning

- Apply a pedagogical principle or tool to the identified element

- Argue briefly how the chosen principle or tool is expected to enhance student learning

Fig. 1: The learning goals of InTeL

The design of the course is rooted in these learning goals and provides participants with the opportunity to work with a specific task or element and thereby making participating in the course relevant and praxis oriented. The course is build in the LMS as an online course running over one week and moderated by e-moderators. This will meet the requirements of cost-effectiveness, scalability, flexibility in time, place, and pace as well as making an exemplary course in Blackboard (conditions $1,3,4$, and 7 ).

In order to meet the requirements 5 and 6 concerning relevance and applicability, the course consists of three parts:

1 An introduction to the course including an endorsement by the pro-rector

2 A mandatory learning path providing general insight into quality in teaching and active learning with three activities along the path

3 A specialised learning path letting the participants choose between five themes (Lecturing, Small Class Teaching, Laboratory Teaching, Clinical Teaching or Supervision) finalized by a written assignment. Participants are further obligated to collect and document feedback from colleagues in their environment

For participants the elements will unfold gradually. Completion of each activity will open up the next part of the course. By the end of the course an automated file with all answers and reflections will be generated for the participating educator to read as a whole.

All activities are leading the participating educator towards a deeper understanding of his or her own teaching practice and the opportunities for designing teaching for enhanced student learning. Thus the course is not a detached activity but a structured way of preparing for the next meeting with students at a higher level of understanding.

However it is important to stress, that the level of the course is designed to be very fundamental. InTeL is the steppingstone into all other professional development courses offered by the institution. 


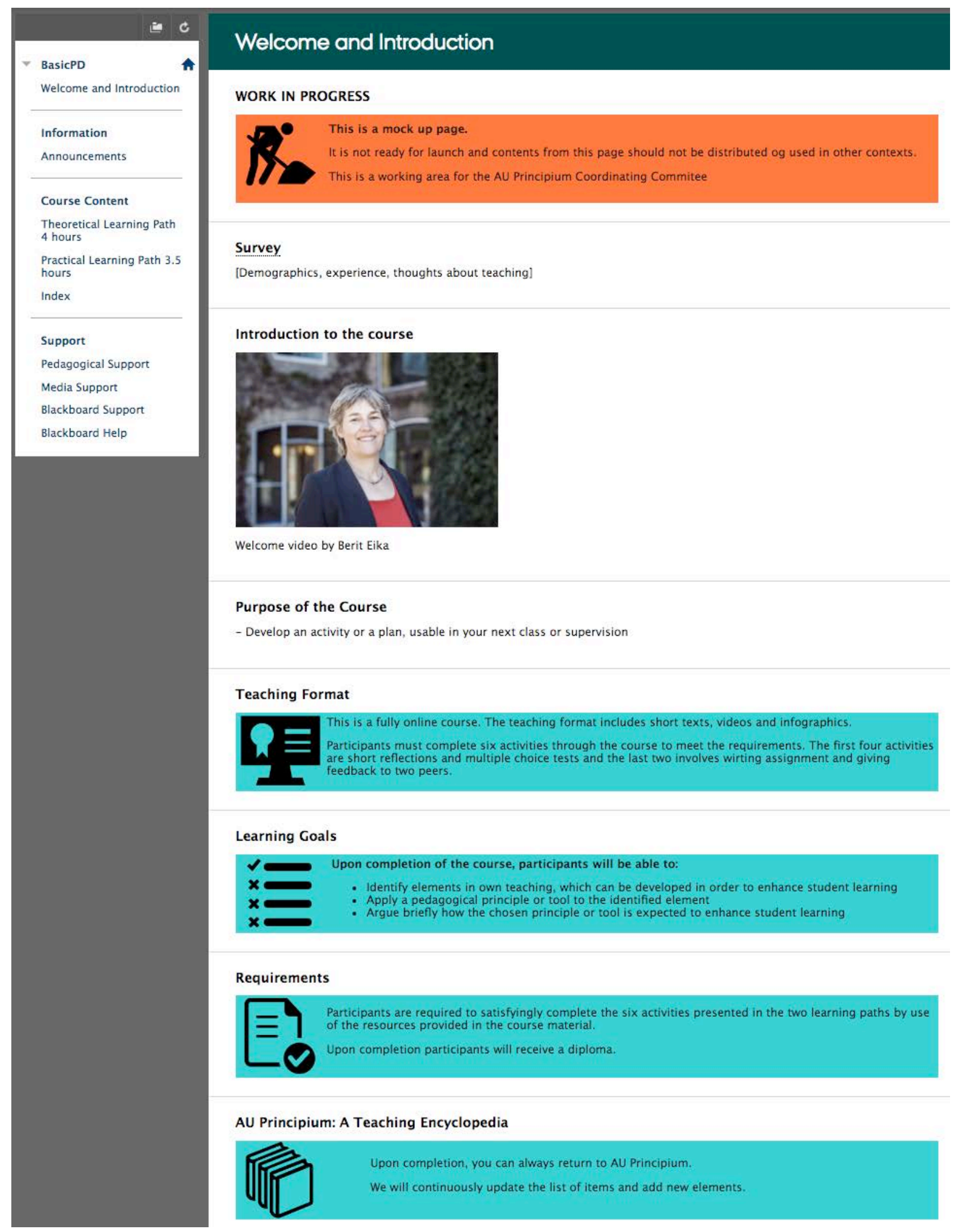

Fig 2: Screen dump of the mock up page of the course. Left margin presents the course elements and the main frame presents the introductory elements

The general outline of the course is presented in Fig. 3: 


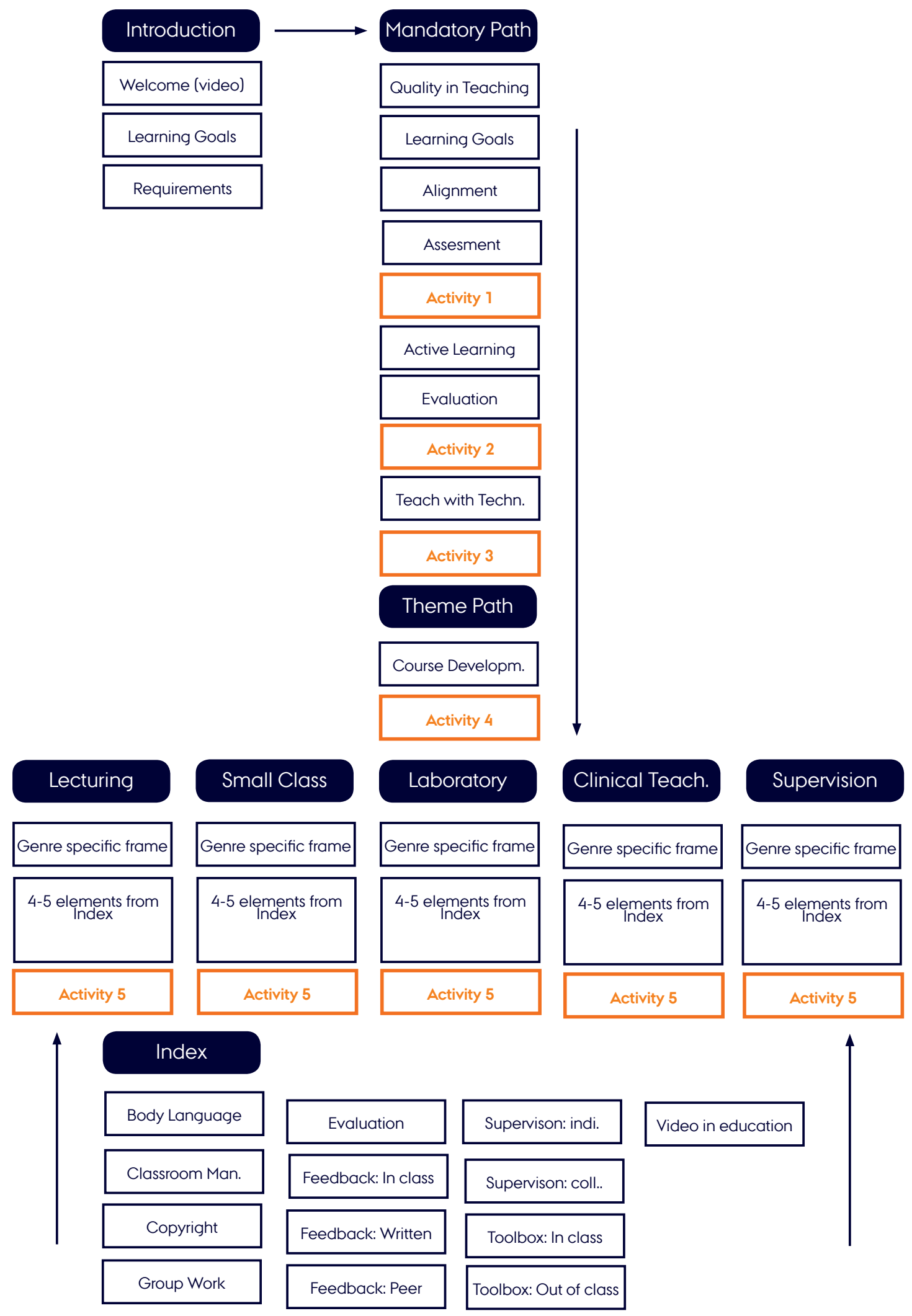

Fig. 3: The outline of the InTeL-course.

The organization behind the course is that of an academic journal. This format was chosen in order to meet condition 8. Choosing a known format for organizing the work provide both familiarity and credibility to the organization. Once running, the course will have an editorial board consisting of one member from each pedagogical centre, a number of content providers and a number of reviewers. 
Further a secretary is involved in the administration of the course and a number of e-moderators affiliated. Fig. 4 illustrates the organisation of the course development group:

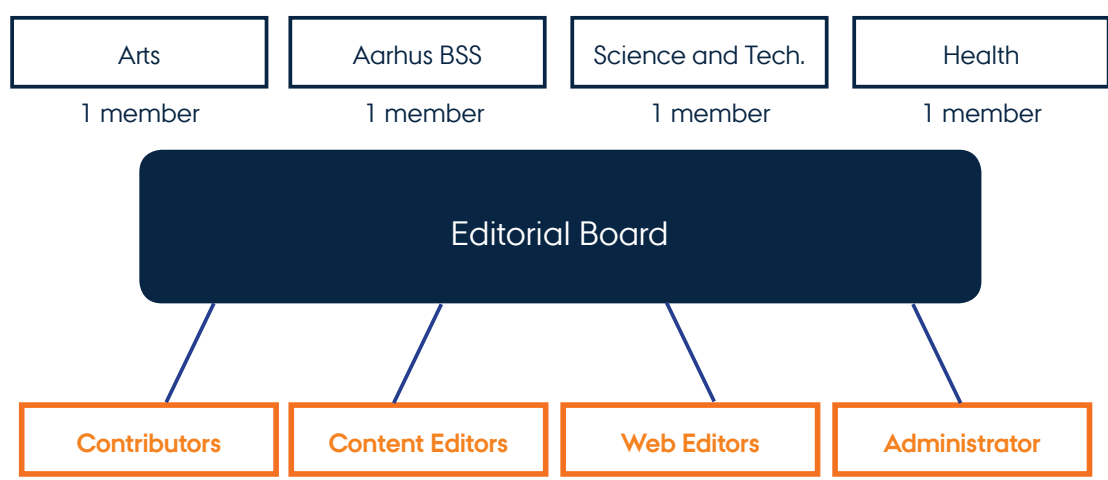

Fig. 4: The organisation of the future developmental work

As the wish for a professional development course is the result of a top-down decision based in an extrinsic demand from the institution of accreditation rather than a bottom-up wish from educators, and as it there will be only one course targeting the whole university, local differences must be addressed. Some faculties will make the course mandatory to all new teaching staff and others will use it as an offer. Some will use the course in close connection to other courses e.g., as the introduction to a longer course and some will only use it stand-alone. It is paramount for the success and use of the course that these local differences can be accommodated in a way, which is not visible to the participants in the course and without having to run four different courses.

In sum, the course is designed to meet the ideal of overcoming not only first- (extrinsic) and second(intrinsic) but also third-order barriers in terms of motivating teachers to see themselves as learning designers and to provide them with basic skills in designing learning activities focusing enhancement of student learning. As pointed out by Kirkwood and Price [6] in their review of technology enhanced learning and teaching in higher education, technology should be a game changer. Both with regards to means and methods, university teaching needs to move away from replacing offline activities with technology enhanced activities. A professional development course like this one is a potential stepping-stone into changing the mindset of the future generation of university teachers. An early introduction to blended learning both in theory and through the course itself would ideally move teachers in the direction of thinking about teaching as design and about technology enhanced teaching as an opening towards new formats and activities rather than merely replacing offline teaching activities with similar online formats. Together with an updated strategy on educational technology this in turn will benefit teachers as well as students.

\section{CONCLUSIONS AND FUTURE INITIATIVES}

In general, developing the design of the InTeL-course and its content has been smooth in spite of a few managerial issues and hidden agendas. Most significant was the mixed interest in the course and its potential role on the different faculties. This may be due to the fact that some units already provides programmes covering the aim of the course and as such felt little need for yet a new module that would potentially render their existing initiatives redundant or had special (and conflicting) interests in developing materials that should be better used elsewhere.

Nevertheless, now that the course is developed and ready for pilot testing, it is the hope that the course will attract a large number of educators. This in turn will provide the pedagogical units with data on the participating educators. Over the run of the first year is it to be expected that more than 100 educators will partake in the course. The challenges they face and the designs they chose to develop will provide previously unreachable data. This knowledge will be valuable both for research and for developing targeted courses and workshops for educators. In this way a top-down decision on onesize-fits-all professional development will potentially lead to more specialised and targeted initiatives in the future. 


\section{ACKNOWLEDGEMENTS}

The authors would like to thank the InTeL coordinator team, Rikke Frøhlich Hougaard and Mads Ronald Dahl as well as the InTeL project group and contributors to the course development.

\section{REFERENCES}

[1] Danmarks Akkrediteringsinstitution (2014). Vejledning om institutionsakkreditering for videregående uddannelsesinstitutioner under Kulturministeriet. Retrieved from http://akkr.dk/wpcontent/uploads/akkr/Vejledning-om-institutionsakkreditering-for-videreg\%C3\%A5endeuddannelsesinstitutioner-under-Kulturministeriet.pdf

[2] Dorst, K. (2011). The core of "design thinking" and its application. Design Studies, 32(6), 521532. http://doi.org/10.1016/j.destud.2011.07.006

[3] Ertmer, P. A. (1999). Addressing first-and second-order barriers to change: Strategies for technology integration. Educational Technology Research and Development, 47(4), 47-61.

[4] Tsai, C. C., \& Chai, C. S. (2012). The "third"-order barrier for technology-integration instruction: Implications for teacher education. Australasian Journal of Educational Technology.

[5] Biggs, J. B. (2011). Teaching for Quality Learning at University: What the Student Does. McGraw-Hill Education (UK).

[6] Kirkwood, A., \& Price, L. (2014). Technology-enhanced learning and teaching in higher education: what is "enhanced" and how do we know? A critical literature review. Learning, Media and Technology, 39(1), 6-36. http://doi.org/10.1080/17439884.2013.770404

[7] Bjælde, O. E., Caspersen, M. E., Godsk, M., Hougaard, R. F., \& Lindberg, A. B. (2015). Learning design for science teacher training and educational development. Globally connected, digitally enabled. Proceedings ascilite.

[8] Godsk, M. (2010). Go online-om effektiv, undervisercentreret udvikling af e-læring ved Aarhus Universitet. Tidsskriftet Læring og Medier (LOM), 3(4).

[9] Godsk, M., Hougaard, R. F., \& Lindberg, A. B. (2013). Teaching Online Teaching Online: Seven Pedagogical Principles for Teacher Training. Proceedings AACE E-learn. 